\title{
Comunicación y construcciones de identidad en el Ángel de Lata (Rosario, 2000-2012)
}

\author{
María Cecilia Telleria \\ Centro de Abordajes Interdisciplinarios de lo Sociocultural, \\ Universidad Nacional de Rosario. \\ telleriacecilia@gmail.com \\ ORCID: https://orcid.org/0000-0002-1971-5968 \\ Fecha de finalización: 22 de marzo de 2021 \\ Recibido: 30 de marzo de 2021. \\ Aceptado: 4 de junio de 2021. \\ DOI: https://doi.org/10.26422/aucom.2021.1001.tel
}

\section{Resumen}

Se aborda desde un enfoque socio-antropológico la construcción del proyecto editorial Ángel de Lata, medio de comunicación gráfico comunitario de la ciudad de Rosario (Santa Fe, Argentina), como un espacio de articulación, identidad y pertenencia orientado por la perspectiva teórica latinoamericana de análisis que relaciona comunicación y cultura. Partimos de considerar que la comunicación, en tanto proceso social que se constituye desde la cultura, va construyendo sentidos de pertenencia e identidad. El proyecto editorial ha intentado, desde sus inicios, generar espacios de trabajo colectivo con organizaciones sociales, cuyas dinámicas generaron diversas concepciones. En este artículo, reseñamos el proceso de construcción del Ángel de Lata, describiendo los distintos lugares por los que ha circulado, revisando las representaciones sociales emergentes desde sus escenarios y retomando las voces de los sujetos sociales que lo conformaron.

Palabras clave: comunicación, identidad, pertenencia, socio-antropología.

\section{Communication and identity-building in Ángel de Lata (Rosario, 2000-2012)}

\begin{abstract}
In this paper, we assess, from a socio-anthropological standpoint, the Angel de Lata editorial project, a grassroots community magazine published in the city of Rosario (Santa Fe, Argentina). It was conceived as a space for discussion, identity-building, and belonging, and was guided by a Latin American theoretical perspective that links communication to culture. From the outset, we understood that communication - as a social process formed within the larger culture - can inspire ideas of belonging and identity. Since the beginning, Ángel de Lata has sought to offer a stage for collective work alongside social organizations, whose dynamics have led to varied visions for the project. We provide an overview of how Ángel de Lata came to be, describing the different places where the magazine has circulated, looking at the emerging social repre-
\end{abstract}


sentations it enabled, and recovering the voices of those social actors who were a part of it. Keywords: communication, identity, belonging, socio-anthropology.

\section{Comunicação e construções de identidade em Anjo de Lata (Rosario, Argentina 2000-2012)}

\section{Resumo}

A construção do projeto editorial Ángel de Lata, meio de comunicação gráfica comunitária na cidade de Rosário (Santa Fé, Argentina), é abordada a partir de um enfoque socioantropológico, como um espaço de articulação, identidade e pertencimento, pautado na perspectiva teórica latino-americana de análise que relaciona comunicação e cultura. Partimos de considerar que a comunicação, como processo social que se constitui a partir da cultura, elabora sentidos de pertença e identidade.

O projeto editorial buscou, desde o seu início, gerar espaços de trabalho coletivo com organizações sociais, cuja dinâmica gerou diversas concepções. Neste artigo, fazemos uma revisão do processo de construção de Angel de Lata que inclui: descrição dos diferentes espaços simbólicos por onde passou, revisão das representações sociais emergentes de seus contextos y retoma as vozes dos sujeitos sociais que o compuseram.

Palavras chave: comunicação, identidade, pertencente, socioantropologia.

\section{Introducción}

En el presente artículo se describirá la construcción del Ángel de Lata como medio de comunicación comunitario gráfico de la ciudad de Rosario (Santa Fe, Argentina), remarcando su constitución como un espacio de articulación, identidad y pertenencia, dando cuenta de su complejidad, con sus contradicciones y conflictos. Para ello, a partir de un análisis socio-antropológico, consideramos el contexto económico-cultural que lo atraviesa, puntualizando en los distintos lugares que ha circulado y los sujetos sociales que han formado parte desde su surgimiento.

El proyecto editorial Ángel de Lata, como medio de comunicación social, surgió en 2000 en la ciudad de Rosario, producto del trabajo de colectivos sociales, tales como las prácticas comunitarias de la institución salesiana Don Bosco y la Agrupación La Vagancia en el barrio Ludueña, la Coordinadora de Trabajo Carcelario y la radio comunitaria Aire Libre (Centro de Educación, Comunicación y Biblioteca Popular). Desde su surgimiento y hasta fines de 2012, la revista intentó llegar a una frecuencia bimestral, no obstante, este cometido nunca se logró por cuestiones económicas. Tenía como frecuencia un promedio de $1 \mathrm{o} 2$ revistas por año, y en sus 16 páginas presentaba secciones que visibilizaban el proyecto comunitario que promovía y a las familias que vendían la revista, como por ejemplo Historias de vida, que trataba de la biografía de la persona involucrada en el proyecto editorial, de dónde venía, cuál era su situación particular. Otra sección era La voz de los chicos, en la que niños y adolescentes contaban su historia y su presente. 


\section{Austral Comunicación \\ Volumen 10, número 1 (junio de 2021): 243-276 ISSN (I) 2313-9129. ISSN (E) 2313-9137}

La publicación era producida por el director y la editora, y desde el espacio de los talleres se producía material sobre las actividades que se realizaban, que era enviado a publicar. En este sentido, en sus páginas se buscó generar una agenda alternativa a la de los medios masivos de comunicación en temas sociales, económicos y culturales. Esto se reflejó, además, en los artículos escritos por periodistas que colaboraron con el proyecto sobre la problemática de la memoria, los derechos humanos y la penalización de menores, entre otras. En otro sentido, en la práctica, buscó aportar económica y socialmente a los sectores vulnerados de la ciudad de Rosario, ya que, por un lado, parte de la venta de la revista era para ellos (comenzando desde 1 peso, 75 centavos "pal'que la vende") y, por el otro, se generaban espacios de contención, educativos y recreativos.

Así, el Ángel de Lata se constituyó a partir de tres objetivos, en los que se condensaron expectativas y representaciones tales como: el ideal de constituirse en una herramienta de trabajo que posibilite paliar las dificultades económicas de familias de barrios periféricos de Rosario y difundir a través de sus páginas estas realidades, generar contención afectivo-educativa en sus participantes y constituir espacios de expresión y educación a través de actividades que se desarrollaron en los tres escenarios donde la revista se difundió: el barrio Ludueña, la Plaza Pringles y, luego de 2010, la Casa del Estudiante.

El campo de conocimiento de los medios de comunicación comunitarios gráficos ha sido abordado desde diferentes enfoques teórico-metodológicos provenientes de las ciencias sociales, mayormente desde la comunicación social (Araujo Albrecht, 2009; Díaz et al., 2002; Franco, 2002; Gutner, 2016; Heram, 2008; Marioni, 2018; Melella, 2010; Sigarusa, 2006; Wilkis, 2006).

La observación participante y las entrevistas en profundidad ${ }^{1}$ que se realizaron durante el proceso investigativo permitieron conocer el proyecto editorial Ángel de Lata, las condiciones de producción, las prácticas socio-culturales y las representaciones que fue construyendo desde sus inicios, en 2000, hasta su último número, a fines de 2012. El proceso que nos ocupa se relaciona con la carencia de estudios sobre el tema desde la perspectiva socio-antropológica, que prepondera a los sujetos sociales implicados en el proyecto editorial, atravesado por historias y contextos diversos que lo fueron construyendo. Lo anterior enriquece su importancia particular y, al mismo tiempo, posiciona a la problemática como parte de los movimientos sociales que surgieron producto de la crisis de 2001 en Argentina. De esta manera, se comprende al Ángel de Lata desde lo comunicacional, lo económico y lo educativo, ya que comunicación, trabajo y educación fueron tres objetivos y tres maneras de concebir al proyecto desde

El trabajo de campo realizado comenzó en 2007 y finalizó en 2012, fecha en la que dejó de publicarse. Se realizó para la tesina de grado de la licenciatura en Antropología, titulada "El Proyecto editorial Ángel de Lata. Abordaje antropológico de un espacio de articulación, identidad y pertenencia en la ciudad de Rosario" (fecha de defensa: 2019). 
María Cecilia Telleria

Comunicación y construcciones de identidad en el Ángel de Lata (Rosario, 2000-2012)

dentro, desde los sujetos sociales que lo conformaron, proceso que no estuvo exentos de conflictos, contradicciones y transformaciones.

\section{Breve estado del arte}

A continuación se recuperan investigaciones que han analizado medios de comunicación gráficos que son producto de construcciones colectivas, semejantes al proceso que aquí se presenta, siendo el campo analítico de la comunicación social predominante en estos estudios.

Franco (2002) analiza qué tipo de identidad, con relación a los vendedores, se intenta construir desde la revista Hecho en Buenos Aires (HBA); de qué forma la problemática de los sin techo es tratada y presentada desde los contenidos de la publicación. Con el objetivo de conocer HBA, describe: quiénes son las personas que la venden, cuál es su trayectoria laboral y personal, qué tipo de vínculo entablan con la revista, cómo viven estas personas la experiencia de venderles a los transeúntes en la vía pública una revista de las "personas de la calle", qué características y alcances tiene la inclusión social propuesta por la revista y cómo es el proceso de armado, edición, venta y distribución de la revista. Con herramientas antropológicas, como las entrevistas semiestructuradas, las observaciones participantes y no participantes y a través de la teoría de la enunciación, se trabajó con la noción de "contrato de lectura" (Verón, 1985) para analizar la estrategia discursiva que entabla HBA con sus lectores y para dar cuenta del tipo de enunciador y destinatario construido en esa relación.

Desplazando al medio y centrándose en los espacios que habilita para realizar prácticas comunitarias, Díaz et al. (2002) exponen los resultados de una investigación cualitativa, en la que se propusieron analizar las experiencias con los jóvenes, adolescentes y niños trabajadores (JANT) en el ámbito de la Fundación La Luciérnaga, utilizando como herramienta metodológica principal la observación participante. De sus reflexiones y testimonios se pudo identificar como uno de los principales problemas "la fuerte incidencia del 'juicio social de la mirada' en la construcción de su propia identidad" (Díaz et al., 2002, p. 4). Considerando que son conocidos como los "chicos de la calle", les genera valoraciones negativas de su propia identidad que los condicionan, pero, a través del trabajo que realizan como vendedores de la revista La Luciérnaga, transforman esos aspectos negativos y mejoran su relación con la comunidad.

Sigarusa (2006) aborda las revistas culturales como documentos de producción colectiva que abarca problemáticas socio-culturales con una posición política, desde la que se puede revisar la historia a través de sus posiciones enunciativas. Analiza particularmente los primeros seis números de la revista político-cultural La Orilla, publicación gratuita de la ciudad de Córdoba, desde noviembre de 2003 hasta fines de 2004. 


\section{Austral @municación \\ Volumen 10, número 1 (junio de 2021): 243-276 ISSN (I) 2313-9129. ISSN (E) 2313-9137}

Wilkis (2006), en un estudio que incluye a la revista Hecho en Buenos Aires, analiza los principios que hacen circular bienes desde los donantes hacia los receptores que intervienen en este circuito. De esta manera, discute con las posturas que conciben a estas prácticas desde el "altruismo", ya que el hecho de que sean gratuitas y desinteresadas problematizaría esta noción, por lo que las concibe como un "don organizado". Comienza historizando la experiencia de las publicaciones de la calle a nivel internacional a fines de los 90, en particular el caso de HBA. Remarca que: "Es interesante plantear que los objetivos que sostiene esta organización se pueden interpretar en función de un intercambio singular que expresa la naturaleza filantrópica de la propuesta de las publicaciones de la calle" (Wilkis, 2006, p. 111).

Heram (2008) analiza el discurso periodístico sobre los medios masivos de comunicación en la revista El Porteño en el período que va de 1982 a 1987. Este medio gráfico, caracterizado como periodismo cultural de carácter alternativo, comenzó a circular hacia fines de la última dictadura militar en la Argentina. Parte de suponer que El Porteño, junto con otras revistas culturales de la época (Humor, Punto de Vista, Crisis), constituyen espacios de debate cultural y de construcción orientadora del gusto masivo.

Araujo Albrecht (2009) pone el acento en la dimensión comunicacional del trabajo social realizado por La Luciérnaga. A partir del análisis de las revistas del periodo 1995-2006, entrevistas y observaciones participantes, pudo evidenciar un proceso de transformación en la organización. Nacida como un proyecto de comunicación alternativa, se fue produciendo en la publicación un proceso de institucionalización: "El medio terminó convirtiéndose en un fin. De herramienta de transformación a fuente de trabajo" (Araujo Albrecht, 2009, p. 137), una empresa social en la que el paradigma que ponía como centro de las decisiones institucionales a los chicos fue desplazándose, generando nuevos procesos de inclusión y exclusión. Excluidos de los ámbitos de decisión sobre el contenido de la revista, sin poder opinar ni participar en los espacios de decisión, los jóvenes se fueron convirtiendo en simples vendedores de la revista en una práctica tildada por la autora de "asistencialista". Es así que "en el proceso de institucionalización que sufre La Luciérnaga, el emprendimiento finalmente adquiere las mismas prácticas de los sectores hegemónicos, generando nuevos estigmas y procesos de discriminación hacia el que fuera su colectivo social originario" (p. 139).

Melella (2010) analiza el periódico Renacer como prensa migrante, considerándolo desde los planteos de Ángel Rama en su libro La ciudad letrada, de 1984. Este último sostiene que las ciudades americanas han tenido una doble vida desde sus asentamientos: por un lado, la ciudad real, sensible y material; por el otro, la ciudad letrada, que corresponde al territorio de lo simbólico. Así, el periódico Renacer "construye (y exhibe) a la colectividad boliviana dentro de las ciudades argentinas y manifiesta un territorio 
simbólico de sentidos, valores y saberes que tienen que ver con la identidad de los migrantes de ese país vecino" (p.3).

Gutner (2016) indaga la representación de la cultura en el discurso de los indigentes en la revista Ángel de Lata, a partir del análisis crítico del discurso en relación con la teoría de las representaciones sociales, considerando que todo texto es una práctica social:

Como "pobres", a través de la representación discursiva, refuerzan la idea de ser considerados sujetos dentro de la sociedad en la que viven. Se trata de la necesidad de que, sus competencias como personas sean reconocidas; es una demanda de subjetividad que surge en todo proceso de construcción de la identidad personal. (p. 34)

Por último, Marioni (2018) reflexiona acerca de la inserción de las juventudes en prácticas mediáticas de comunicación comunitaria, alternativa y popular, a partir de un relevamiento de medios y experiencias juveniles pobres en la región centro de la Argentina. La autora reconoce que estas experiencias comunicacionales "aportan a la emergencia de formas políticas alternativas a las dominantes en las que se constituyen procesos de subjetivación juveniles que les permiten a sus actores cuestionar su adscripción social y política" (p.39).

\section{Lo teórico-metodológico: entendiendo la comunicación desde la cultura}

La centralidad del trabajo conceptual dentro de la etnografía está relacionada con la posición epistemológica [...] se observa y se describe, necesariamente, a partir de determinada concepción del objeto. (Rockwell, 2011,p. 92)

Se considera al objeto de las ciencias sociales como histórico, en un determinado tiempo/espacio y en constante transformación, reconociendo a los sujetos sociales como poseedores y constructores de una conciencia histórica.

En Marxismo y literatura, Raymond Williams (2009) se propone analizar la teoría marxista de la cultura, que lo lleva a cuestionar la lectura mecanicista que han efectuado los marxismos sobre la dicotomía base/superestructura. Por lo tanto, focaliza en las cuestiones de la "determinación", entendida como un proceso de "fijación de límites" y "ejercicios de presiones". Es así que la cultura, "proceso social total", debe pensarse dentro de esta determinación, en la que se producen configuraciones y conceptualizaciones en torno a ese proceso, en el que intervienen mecanismos de distribución de poder. La cultura se articula así con el proceso de hegemonía. Retomando los postulados de Gramsci, Williams (2009) postula que la hegemonía constituye:

[...] todo un cuerpo de prácticas y expectativas en relación con la totalidad de la vida: nuestros sentidos y dosis de energía, las percepciones definidas que tenemos de nosotros mismos y de nuestro mundo. Es un vívido sistema de significados y valores -fundamenta- 


\title{
Austral Comunicación \\ Volumen 10, número 1 (junio de 2021): 243-276 ISSN (I) 2313-9129. ISSN (E) 2313-9137
}

\begin{abstract}
les y constitutivos- que en la medida en que son experimentados como prácticas parecen confirmarse recíprocamente. [...] Es un sentido de realidad [...] en el sentido más firme, es una "cultura", pero una cultura que debe ser considerada asimismo como la vívida dominación y subordinación de clases particulares. (p. 151)
\end{abstract}

La definición de "hegemonía" desarrollada por Williams (2009) permite analizar la desigualdad social y las relaciones de poder que promueven los sentidos en el "proceso social total" de producción de significados. Asimismo, habilita comprender a la comunicación desde su espesor cultural, como postula Martín Barbero (1991): “[...] de los medios a las mediaciones, esto es, a las articulaciones entre prácticas de comunicación y movimientos sociales, a las diferentes temporalidades y la pluralidad de matrices culturales" (p. 203).

Se arriba a una conceptualización de la comunicación en tanto espacio estratégico de poder y lucha por los sentidos (Martín Barbero, 2004), que conlleva considerar que lo hegemónico implica necesariamente una "contrahegemonía o hegemonía alternativa" (Williams, 2009, p. 155). Estas formas contrahegemónicas existen en la sociedad como elementos significativos, por lo que "[...] la función hegemónica decisiva es controlarlas, transformarlas, $\mathrm{o}$ incluso incorporarlas [...] puede sostenerse que la cultura dominante, por así decirlo, produce y limita a la vez sus propias formas de contracultura" (Williams, 2009, pp. 156-157). La hegemonía resulta así un proceso activo, una interconexión y organización de significados, valores y prácticas.

Williams (2009) utiliza el concepto de estructuras de sentimientos para poder comprender los significados, valores y prácticas desde su formación, tal como son vividos y sentidos activamente desde una conciencia práctica presente, siendo que "[...] toda conciencia es social, sus procesos tienen lugar no sólo entre, sino dentro de la relación y lo relacionado" (p. 178). Significarla como estructura lleva a considerarla "[...] como una serie de relaciones internas específicas, y a la vez entrelazadas y en tensión” (p. 181).

Este autor destaca el proceso formativo que define una experiencia social; no son estructuras fijas y establecidas, sino que están "presentes" en una continuidad socialmente interrelacionada. De esta manera, se puede comprender el proyecto editorial Ángel de Lata como parte del proceso material y social, "[...] como una formación social de tipo específico que a su vez puede ser considerada como la articulación de estructuras de sentimiento que como procesos vivientes son mucho más ampliamente experimentadas" (Williams, 2009, p. 183).

En este trabajo, la comunicación es entendida como un proceso social de producción, intercambio y negociación de universos culturales. Definir la comunicación desde esta perspectiva se ubica en la línea de pensamiento latinoamericano de los investigadores de la comunicación (García Canclini, 1995; Martín Barbero, 1991; entre 
María Cecilia Telleria

Comunicación y construcciones de identidad en el Ángel de Lata (Rosario, 2000-2012)

otros), que apunta a trascender el aspecto estrictamente técnico y del desarrollo de habilidades tanto de elementos discursivos como de los medios, para ubicarlo sobre todo en el espacio de las relaciones entre sujetos, enmarcados en contextos sociales y culturales (Martín Barbero, 2004).

Por consiguiente, se concibe el proyecto editorial Ángel de Lata como medio de comunicación comunitario dentro de esta concepción de la realidad social y cultural que posibilita comprenderlo inmerso en un entramado socio-histórico, el cual desde sus inicios ha sido conformado por distintos sujetos sociales, generando espacios de articulación, identidad y pertenencia, tanto desde su materialidad como en las prácticas sociales que ha habilitado.

La comunicación, como posibilitadora de las relaciones sociales y/o de la sociedad, es uno de los hechos fundamentales que recuerda que "somos con el otro", lo que conlleva también cuestiones de identidad. Estas son entendidas no como esencias estancas, sino de manera relacional; son procesuales, históricas e implican relaciones de poder, son asignadas, asumidas o construidas de manera flexible o impuestas (Castells, 2004). Implican, además, un sentimiento de pertenencia, dado que al interior de una organización social se comparten ciertos universos de significado, los cuales se conforman como representaciones sociales (Giménez, 1997; Hall y Du Gay, 2003). En esta línea, "el concepto de identidad aquí desplegado no es, por lo tanto, esencialista, sino estratégico y posicional" (Hall y Du Gay, 2003, p. 17). Hall entiende la identificación como un proceso de articulación y no una subsunción, en el cual las identidades se construyen de múltiples maneras a través de discursos y prácticas diversas, por lo que está sujeto tanto a los procesos históricos como a procesos de cambio y transformación.

Por su parte, las representaciones sociales serán siempre estructuradas y definidas dentro de un contexto histórico-social, que servirán como "marcos de percepción y de interpretación de la realidad, y también como guías de los comportamientos y prácticas de los agentes sociales" (Giménez, 1997, p. 15).

Las identidades ponen en juego prácticas de asignación y de identificación. En este sentido, la identidad se relaciona con las categorías de pertenencia social. Al respecto, Giménez (1997) define a la pertenencia social como: “[... la inclusión de la personalidad individual en una colectividad hacia la cual se experimenta un sentimiento de lealtad" (p. 13).

Con esta orientación, se concibe que la comunicación, como proceso cultural, posibilita la construcción de espacios de articulación, identidad y pertenencia. El proyecto editorial Ángel de Lata intentó, desde sus inicios, generar esos espacios a partir del trabajo colectivo de organizaciones sociales, en los que surgieron distintas maneras de concebirlo que lo fueron definiendo como tal. Esta investigación permitió entrever las 


\section{Austral @municación \\ Volumen 10, número 1 (junio de 2021): 243-276 ISSN (I) 2313-9129. ISSN (E) 2313-9137}

representaciones sociales que se fueron construyendo desde los distintos escenarios y sujetos sociales que lo conformaron.

El enfoque teórico-metodológico utilizado corresponde al enfoque etnográfico y/o relacional, en el cual se privilegia el trabajo de campo como así también su complementación simultánea con la teoría, dentro de un proceso que involucra la reflexividad del sujeto investigador con sus sujetos de estudio (Rockwell, 2011). De esta manera, el conocimiento se construye a través de una relación dialéctica entre el trabajo de campo y la teoría como "procesos paralelos y entrelazados" (p. 47), en los que sus herramientas metodológicas son la observación participante y la entrevista en profundidad. El trabajo de campo resulta imprescindible en este enfoque cualitativo, ya que es una manera de comprender a esos "otros" estando entre ellos. No se trata de estudios de caso, sino de estudios en caso, como plantea Geertz (como se cita en Achilli, 2005), considerando así el contexto histórico-social en los que los procesos observados se inscriben.

\section{Escenarios de una construcción: Ángel de Lata}

El proyecto editorial Ángel de Lata surgió en 2000 en la ciudad de Rosario, a partir del trabajo y prácticas comunitarias de la institución salesiana Don Bosco, la Agrupación La Vagancia en el barrio Ludueña, la Coordinadora de Trabajo Carcelario y la radio comunitaria Aire Libre.

En esos años, comenzaron a emerger publicaciones de las calles en distintas partes del globo, conformándose la Red Internacional de Publicaciones de la Calle. Se trata de emprendimientos originados por instituciones $y / u$ organizaciones no gubernamentales que buscaban otras alternativas a las tradicionales lógicas asistencialistas del Estado, atendiendo a la emergencia económica de los estratos poblacionales, otorgándoles una herramienta de trabajo y un espacio de pertenencia. De esta manera, los vendedores de las diferentes publicaciones representan las particularidades de la "exclusión" en cada ciudad (Wilkis, 2006), pero, al mismo tiempo, se configuran como espacios desde los cuales visibilizar otras realidades que no son las que circulan en los medios masivos de comunicación, o se las trata desde otra perspectiva, con la intención de que sus contenidos despierten "conciencia social" (Barturen, 1997).

El inicio de este proyecto no fue un hecho aislado en la Argentina, sino que fue producto de procesos de reconfiguración económica y cultural que arrancaron en los 70 y comenzaron a ser visibles en los 90 , década durante la cual se profundizaron las reformas neoliberales que generaron un período de exclusión social y desigualdad: nuevos pobres, desocupados que fueron abandonados al vagabundeo y a la venta ambulante (Araujo Albrecht, 2009). Ya en 2001, el convulsionado escenario social se presentó como un espacio idóneo desde el cual tramar estrategias de representación 
y de acción colectivas: movimientos de desocupados, asambleas barriales, fábricas recuperadas por sus trabajadores y movimientos culturales, entre los que resaltamos el surgimiento de varios proyectos editoriales.

Se puede pensar que estas acciones colectivas expresan lo vivido históricamente en el proceso social total (Williams, 2009). Es así que estos proyectos editoriales posibilitan pensar a la comunicación no solo como una cuestión de medios, sino desde su espesor cultural, desde las matrices culturales, los espacios sociales y las operaciones comunicacionales de los diferentes actores (Martín Barbero, 2004) dentro de procesos concretos de hegemonía/subalternidad.

Nos detendremos en la historia de construcción del proyecto editorial Ángel de Lata, transitando los tres escenarios por los que ha circulado -el barrio Ludueña, la Plaza Pringles y la Casa del Estudiante de la ciudad de Rosario-, visibilizando las dinámicas y las representaciones sociales que se han ido constituyendo.

\section{Primer escenario: barrio Ludueña}

El barrio Ludueña de la ciudad de Rosario presenta una historia de configuración que se retrotrae a la década del 40 , en la cual se fue poblando de inmigrantes extranjeros; y en las últimas décadas, de familias venidas de provincias del norte de la Argentina en busca de trabajo (Alucín y Denardi, 2012). Estas corrientes migratorias alimentaron una fisonomía barrial compleja y presentaron problemáticas que giran en torno a "la delincuencia juvenil, las adicciones, los enfrentamientos entre bandas y pandillas, el abuso policial, la impunidad, la falta de acceso a la salud, el difícil acceso a una atención jurídica, situaciones de violencia familiar" (Alucín y Denardi, 2012, p. 4).

Ante esto, el barrio Ludueña se presentó como un territorio propicio para el trabajo de la institución salesiana Don Bosco. El referente más emblemático de esta labor fue el sacerdote salesiano Edgardo Montaldo, integrante del movimiento de curas tercermundistas. Considerando las problemáticas de exclusión y violencia, y a los niños y jóvenes como los destinatarios predilectos del trabajo comunitario, fueron construyendo el comedor y la escuela. En este contexto, en la década del 90, se formaron distintas organizaciones socio-políticas que se articularon en los espacios del barrio.

Junto con la labor del padre Montaldo, a fines de los 90 apareció otro referente, Claudio "Pocho" Lepratti, ${ }^{2}$ quien comenzó a organizar diferentes grupos de jóvenes, en lo que se llamó la Coordinadora Juvenil de la Vicaría Sagrado Corazón, desde la cual se organizaban campamentos y talleres educativos, religiosos y recreativos. En esa articulación de personas, militantes de los derechos humanos que trabajaban junto al padre

\footnotetext{
El "Pocho" fue asesinado por la policía de Santa Fe durante la crisis y represión de 2001 que azotó a todo el país Este hecho alcanzó notoriedad a través de la canción de León Gieco El ángel de la bicicleta, en la que se visibiliza la popularidad del "Pocho" antes y después de su asesinato.
} 


\section{Austral Comunicación \\ Volumen 10, número 1 (junio de 2021): 243-276 ISSN (I) 2313-9129. ISSN (E) 2313-9137}

Montaldo en la vecinal del barrio, los jóvenes de la Agrupación La Vagancia, coordinado por Lepratti, la radio comunitaria Aire Libre (Centro de Educación, Comunicación y Biblioteca Popular) y la Coordinadora de Trabajo Carcelario (CTC) se movilizaron ante la realidad del barrio y comenzaron a delinear el proyecto editorial Ángel de Lata.

Fue allí, en esos espacios compartidos, donde comenzaron a visualizar como problemática la falta de trabajo. Así lo expresa un editor de ese momento: "Empezamos a pensar en conjunto sobre posibles alternativas o el trabajo en función a lo que hacía a ese problema, la falta de laburo" (A, comunicación personal, 31 de junio de 2012).

Una de las organizaciones que estuvieron en estos comienzos fue la sociedad civil denominada Centro de Educación, Comunicación y Biblioteca Popular, más conocida localmente como radio comunitaria Aire Libre. Se trata de una radio comunitaria que comenzó a gestarse en los 90; con el transcurso de los años, sus integrantes fueron haciendo realidad otros proyectos, como la Biblioteca Cachilo y diversos talleres. Lepratti organizaba, junto a la juventud del barrio Ludueña, la experiencia del periódico $L a$ Nota y La Notita como espacios de construcción de sentidos, que eran realizados por los propios pibes a través de la participación en talleres de comunicación popular, con la colaboración de la radio Aire Libre. Un integrante de la radio, relata:

\footnotetext{
En ese momento, había gente que uno iba conociendo, gente permanentemente en esto, gente que venía y nos decía "che, tengo tal cosa si a ustedes les sirve, si les gustaría tener". [...] Otra gente también nos donó un mimeógrafo [...] No lo pudimos usar porque estamos más en radio que en gráfica. Entonces fue en ese momento que Pocho estaba trabajando con los chicos allá en Ludueña, año 96, 97, que se empezó a acercar porque le habían dicho que nosotros teníamos un mimeógrafo y ellos querían sacar una revista que en ese momento se llamaba La Notita, pero no tenían cómo imprimir. Entonces es como esto: "che, por qué no hablás con los compañeros de tal que tienen, fijate si lo usan" y ahí aparece Pocho, ¿viste? Y nos contó lo que quería hacer y dijimos "mirá, flaco, no sé, está ahí, qué se yo, usalo, nosotros lo tenemos acá si a ustedes les sirve". (B, comunicación personal, 9 de agosto de 2012)
}

Otro de los organismos que participaron activamente desde sus comienzos fue la CTC, "la coordinadora es un espacio en donde trabajan muchas organizaciones, anarquistas, de HIJOS, APDH [Asamblea Permanente por los Derechos Humanos], agrupaciones que trabajan sobre los derechos humanos" (V, comunicación personal, 17 de julio de 2007). La CTC hacía trabajos en el barrio Ludueña a través de una consultoría jurídica. "L", editora de la revista e integrante de la CTC, expresa:

La consultora jurídica tenía que ver con la situación de generar vínculos con la familia que tenían los chicos presos, y las situaciones con la policía que se daban en los barrios. Por otra parte, a partir de eso, también nosotros teníamos una serie de encuentros con chicos que ya estaban presos en comisarías y surgió la idea de contactarnos con los chicos antes de que los chicos estén presos. Digamos, como una cuestión preventiva. (L, comunicación personal, 28 de noviembre de 2011) 
A partir de estos vínculos y de las prácticas sociales llevadas a cabo en el barrio Ludueña, comenzó a gestarse el proyecto editorial Ángel de Lata, inspirado en La Luciérnaga, de Córdoba:

En el 2000 creo que fue el momento en el cual se pensó en la posibilidad de hacer una revista $[. .$.$] en base a experiencias que se estaban dando en algunos puntos del país, como$ Córdoba, donde los chicos en situación de calle vendían una publicación que hablaba de ellos y que podían quedarse con un porcentaje de la revista, que era una forma de pensar un financiamiento y una forma de trabajo, digamos, más o menos digna. [...] nos comparten el proyecto a nosotros por el tema de comunicación y para tener el apoyo de organizaciones que estuvieran en la comunicación, que fueran referentes de la comunicación popular [...] es así que participamos de las primeras instancias del proyecto. (B, comunicación personal, 9 de agosto de 2012)

[...] creo que el Tomi le hace referencia a M H de que él estaba colaborando con una revista, La Luciérnaga, haciendo las tapas, y le plantea la posibilidad de hacer una revista de esas características acá en Rosario. Enseguida empezamos a trabajar en ese proyecto. (A, comunicación personal, 31 de julio de 2012)

En este escenario, se contempla al proyecto editorial Ángel de Lata como un medio de comunicación de las realidades vividas en el barrio Ludueña y en otros lugares/espacios, realidades no difundidas por los medios hegemónicos de comunicación. También como una oportunidad económica, una fuente de trabajo, y como una propuesta educativa de contención, de pertenencia de niños y adolescentes, brindando espacios educativos y de expresión a través de talleres.

En ese primer momento, la publicación tenía una clara impronta para los actores sociales de ese escenario: era "hecha por y para los pibes". Esto, que se había convertido en uno de los objetivos del proyecto editorial, significaba que la producción del contenido era realizada por los jóvenes de la Agrupación La Vagancia, acompañados por el colectivo de la radio comunitaria Aire Libre:

\begin{abstract}
nosotros teníamos una frase, que era "hecha por y para los pibes" [...] Era primero hecha por nosotros y después también de alguna manera era para nosotros, pero en realidad nosotros también estábamos pensando en ese momento mostrar en la revista algo que no se estaba mostrando en la ciudad, que era esta cosa de poder conocer qué pasa en los barrios, ¿me entendés? Porque siempre nos inunda con que [...] en los barrios solamente hay falopa, choreo, muerte, bueno, entonces nosotros también lo que tomábamos era esto, era poder sacar del barrio y hacer conocer por fuera del barrio lo que se estaba viviendo en el barrio. (M, comunicación personal, 14 de octubre de 2012)
\end{abstract}

Este objetivo se enlazaba con una concepción del proyecto en clave comunicacional: mostrar lo que no se muestra en los grandes medios o mostrar otras realidades más allá de aquello que se muestra relacionado a cuestiones negativas del barrio. De esta manera, podemos pensar que se trataba de un medio de comunicación comunitario y alternativo, que ha sido caracterizado desde el campo de la comunicación social por proyectarse desde una estructura horizontal, dialógica y participativa frente a la 


\section{Austral Comunicación \\ Volumen 10, número 1 (junio de 2021): 243-276 ISSN (I) 2313-9129. ISSN (E) 2313-9137}

verticalidad de los grandes medios, con un fuerte sentido crítico, contracultural y contrahegemónico, generando otros discursos, otras miradas en contraposición al poder de los medios masivos. Asimismo, estos medios se encuentran asociados a estrategias para un cambio social desde la comunicación de los sectores populares, para que sean reconocidas sus "voces" en el campo mediático (Fasano y Roquel, 2015; Kejval, 2016; Mata, 2000; Vinelli y Rodríguez Esperón, 2004). Al respecto, algunos participantes del proyecto comentaron sobre esta característica de la publicación, que la diferencia de los medios masivos:

[...] si se quiere, es como una voz que tiene que estar presente y que no son esas voces que los medios de comunicación amplifican, ¿no? y que si no estuviera el Ángel de Lata, no se escucharían, o no se leerían, en este caso, porque estamos hablando de una revista [risas]. No se leerían voces o historias tan masivamente, porque es así, el Ángel de Lata es una revista masiva, se vende muchísimo, se difunde muchísimo. Entonces, esas experiencias, ese proyecto que muestra el Ángel o las historias de vida, los ensayos que por ahí también salen sobre derechos humanos, sobre cómo están las causas, la denuncia permanente o el llamado a la memoria de los del 19 y 20 de diciembre del 2001, son un montón de cosas que son fijas y que el Ángel comunica. (R, comunicación personal, 11 de septiembre de 2012)

Sí, el contenido tiene que ver con situaciones que no son tocadas comúnmente en los medios de comunicación tradicionales y que tiene que ver con situaciones particulares que no son de venta masiva, que tiene que ver con el tema. Por ejemplo, para nosotros es muy importante el tema de los chicos privados de la libertad, de los adultos privados de la libertad, el tema de las leyes que tiene que ver con los niños y adolescentes, el tema de los derechos humanos en general, digamos, esas cuestiones, esas problemáticas de los barrios que no tienen en realidad lugar en los medios tradicionales, ¿no?, en los medios de comunicación masivos. Mostrar lo que no se muestra, como medio alternativo. Mostrar [...] o hablar de lo que no se habla en los grandes medios, [...] ese era [...] el objetivo [...] de la revista. (L, comunicación personal, 28 de noviembre de 2011)

Y bueno, con la revista me pareció siempre que la leía de hace un montón de años, que había cosas que estaban muy fuera de la realidad de estos chicos, hablaba mucho de lo de la cárcel y todo eso. Pero también siempre me pareció importante porque yo, al leerla, me enteraba de otras realidades, o la mayoría de la gente que compra la revista ni le importa si los chicos que están presos, menores, están bien o están mal. Esto me pareció buenísimo. (C, comunicación personal, 16 de enero de 2013)

El armado de la revista basado en el precepto "hecha por y para los pibes" era un objetivo que trató de sostenerse, un ideal a alcanzar, pero fue causal de que el grupo fundador del proyecto editorial comenzara a desarmarse. Así fue con la participación de la radio Aire Libre. Ellos sostuvieron reuniones hasta la aparición del primer número de la publicación. Luego, al ver que ese objetivo no se sostenía y que como colectivo tenían otras prioridades y proyectos, se distanciaron del grupo fundador:

[...] el tema es que nosotros queríamos que los chicos fueran los que produjeran la información, porque también estaba la idea de que la revista no se produjera desde los adultos que hablan de los chicos, digamos, sino que los chicos trabajaran conceptos de comunicación y pudieran escribir cosas [...] nos pareció que el rumbo de la revista y la forma en 
que se iba a producir no nos convencía del todo. Entonces como que dijimos "nosotros queremos otra cosa".

- ¿Y de qué forma estás hablando?

- Como que la revista iba a ser trabajada por los adultos y que cuente cosas de los chicos, que a lo mejor sí, eran testimonios de los chicos, pero los chicos no intervenían me parece en la revista con voz propia en el armado y en la producción [...] Teníamos otro concepto de lo que sería, digamos, este, y también porque estábamos con nuestro propio tiempo. (B, comunicación personal, 9 de agosto de 2012)

Para la Agrupación La Vagancia también pesó este cambio en la producción de la revista, por lo que se abrieron del proyecto:

Nos organizábamos entre nosotros, y nosotros decidíamos qué iba y qué no iba, ¿viste? Lo discutíamos, teníamos una fuerte discusión y por eso después terminamos todos discutiendo $[\ldots]$ cuando nos parecía $[\ldots]$ que la revista se estaba haciendo [...] desde los grandes. Nosotros, cuando empezamos a ver que la revista la empezaban a hacer los grandes, no nos interesó más, es así. [...] Cuando la revista no fue más de los pibes, nos fuimos. O sea, pasó eso en la revista, por eso nosotros nos fuimos. (M, comunicación personal, 14 de octubre de 2012)

Esta problemática que surgió en el grupo que llevaba adelante el proyecto expresa cuestiones sobre su organización, el armado de la revista y los contenidos que comunicaba:

Ángel de Lata no es un equipo organizado. A veces se juntan, a veces no, es como que no está estructurado y pasa que muchas veces a la revista la termina haciendo L sola en la computadora y la manda a la imprenta. (V, comunicación personal, 17 de julio de 2007)

Que el proyecto editorial no estuviera formado por un equipo estructurado, a través del cual organizar el contenido de la revista con la participación de los chicos y familias que la vendían, hizo que se distanciara de las experiencias comunicacionales alternativas y populares con las características que mencionamos. Igualmente, es posible reflexionar sobre el Ángel de Lata como medio de comunicación alternativo, problematizando los tradicionales espacios de emisor-receptor característicos de los sistemas de comunicación:

La revista va dirigida a un sector más amplio, que tiene que ver con la llegada de determinadas problemáticas de derechos humanos a los compradores de la revista, que es un sector mucho más amplio. Pero, digamos, como proyecto de trabajo es un proyecto para los sectores más postergados [...] de la sociedad. (L, comunicación personal, 28 de noviembre de 2011)

Para el equipo editor, los vendedores eran los receptores y quienes le daban legitimidad al proyecto editorial, más allá de que el armado de la revista no era compartido entre todos los participantes. Así lo expresó una integrante del proyecto: 


\title{
Austral Comunicación \\ Volumen 10, número 1 (junio de 2021): 243-276 \\ ISSN (I) 2313-9129. ISSN (E) 2313-9137
}

\begin{abstract}
Nosotros les hacemos notas a los chicos, ellos cuentan sus historias y demás, pero si yo te digo que las notas las hacen puramente la gente o los chicos es mentira. [...] además no sé si es lo que le daría legitimidad. Lo que le da legitimidad a la revista es esta cuestión de que refleja la realidad de estas familias, de estos chicos, y que es para ellos. Esta revista es para ellos, y yo te digo vos vas a la plaza y preguntás y la inquietud de todo el mundo es hasta cuándo va a durar la revista, y que dure porque hay mucha gente que, sinceramente, come y mantiene sus hogares de eso. Son muchas personas las que comen de ahí, [...] eso es lo que creo, lo que pienso que le da legitimidad. (N, comunicación personal, $28 \mathrm{de}$ agosto de 2007)
\end{abstract}

Esto se relaciona con que la Coordinadora de Trabajo Carcelario, cuando se encargó del Ángel de Lata luego de que los directores se fueran, no puso todo el foco en el proyecto editorial, dado que era uno más entre otros:

\begin{abstract}
-Sí, se tiraban algunas ideas, el Tomi escribía [el] editorial, planteaba la tapa. Aparecía alguna idea, viste que el contenido no son muchas páginas, se llenaba, por ahí costaba, pero a la vez no era demasiado material, yo alguna nota escribía, alguna entrevista, no era la típica redacción de una revista. [...] otra cosa que se buscaba era que los chicos escriban los contenidos, eso tampoco se logró, como que no era muy participativo.

- ¿Sabés por qué era así?

-Yo creo que tiene que ver más con no haber focalizado en el Ángel de Lata [...] por ejemplo, la Coordinadora de Trabajo Carcelario era como yo te decía antes, muchos trabajos, como que no era la única cosa que se hacía desde la Coordinadora, más allá de que había personas [...], por ejemplo yo, que estaba más o menos en el tema, pero era como que faltaba otra estructura. Yo creo que no tenía una estructura de recursos humanos y financiera que sostenga el proyecto en el tiempo. Se sostuvo a los tumbos [...] Se iba más o menos armando, [...] no era como la redacción de una revista que nos juntábamos y hacíamos una asamblea para decidir cosas. (A, comunicación personal, 31 de julio de 2012)
\end{abstract}

En definitiva, el armado de la revista tenía que ver con lograr un producto que reflejara las experiencias de vida o las realidades de las personas que la vendían, que fuera estético en el diseño para que la gente no la comprara por "lástima”. Una integrante de la CTC expresa:

[...] somos cuidadosos en el tema del diseño, las notas, porque interesa que la revista guste, digamos, que la gente la compre porque es linda [...] y porque le interesa y porque es interesante lo que refleja y no por lástima, o sea, nosotros podríamos sacar una revista cada dos meses y reproducir cualquier cosa [...] o hacer algo de mucho menor calidad y garantizaríamos la continuidad, pero la gente se las compraría a los chicos de lástima y lo que nosotros estamos tratando justamente de sacar de la vida de estos chicos es este tema de la lástima, que les tengan lástima, que puedan apostar más [...] a construir una autoestima positiva. (N, comunicación personal, 28 de agosto de 2007)

Si bien en la estructura organizativa no se perciben cuestiones que remitan a las experiencias de los medios de comunicación alternativos ni a un trabajo colectivo, se observa que el contenido estaría manifestando cuestiones de contrainformación, en el sentido que difunden, comunican y denuncian desde una perspectiva crítica cuestio- 
nes sobre derechos humanos en general, chicos privados de la libertad, dictadura y los hechos sucedidos el 19 y 20 de diciembre en particular:

\begin{abstract}
Hay una línea editorial [...] que tiene que ver siempre con una problemática de los chicos. No siempre, y en general también tocamos los temas del trabajo de la Coordinadora de Trabajo Carcelario, como [...] los chicos que están presos en el IRAR, los adultos, la situación en general, la situación económica y el tema de los derechos humanos en general, tanto en lo que es el tema de la memoria, la dictadura y demás como el tema actual. Esa es [...] la línea de la revista, y otra de las líneas que siempre se contempló [...] a partir del 2001 es el tema de diciembre del 2001 y todo lo que tiene que ver con la Comisión investigadora, los crímenes de diciembre y demás. Eso siempre se siguió tocando. Y ahora se cumplen 10 años y justamente en esta revista se va a tratar ese tema. El tema de los diez años del 2001 y la situación de impunidad para la mayoría de los casos. (L, comunicación personal, 28 de noviembre de 2011)
\end{abstract}

\title{
Segundo escenario: Plaza Pringles
}

La Plaza Pringles está ubicada en el microcentro de la ciudad de Rosario, entre las calles Córdoba y Paraguay. Marca el inicio de una de las peatonales de la ciudad, con diversos comercios, donde diariamente circulan muchas personas por trabajo, entretenimiento y/o consumo. Como plaza, constituye un espacio social, un escenario en el cual ocurren diversas escenas simultáneas: vendedores artesanos de paño, inicio de manifestaciones y/o actos, vendedores de plantas y flores, promotoras/es de los boliches de la ciudad y de marcas de consumo. Entre tanta heterogeneidad, la plaza constituía, a su vez, el punto de encuentro de los integrantes del proyecto editorial Ángel de Lata, como también el punto de partida de los vendedores de la revista; para ambos, se fue constituyendo en un espacio de referencia y pertenencia, "la plaza".

Particularmente para los vendedores, este lugar se configuró como un espacio laboral, "el microcentro de la ciudad es la zona que reúne el mayor porcentaje de bienes y servicios finales, por lo tanto representa el espacio que brinda más posibilidades de obtención de beneficios" (Buffarini, 2008, p. 191).

Luego de diciembre de 2001, los directores del Ángel de Lata migraron a Europa y designaron a una colaboradora como continuadora de la revista, miembro de la CTC, llamada " $L$ ", la cual se constituyó como editora. Las organizaciones sociales que antes participaban de la construcción del proyecto se alejaron por no compartir algunas cuestiones que comenzaron a surgir. En el caso de los chicos de La Vagancia, como ya se mencionó, lo que determinó que se retiraran fue "cuando la revista no fue más de los pibes". Como se señaló más arriba, la radio comunitaria Aire Libre también abandonó el proyecto por este hecho.

A partir de ese momento, el espectro de la revista se instaló en el centro de la ciudad de Rosario, lo que provocó cambios en la organización. En la plaza y en el local de la CTC comenzaron a confluir niños y adolescentes. Buscaron vincularse con distintos 


\section{Austral Comunicación \\ Volumen 10, número 1 (junio de 2021): 243-276 \\ ISSN (I) 2313-9129. ISSN (E) 2313-9137}

espacios, como AMSAFE, ATE, la Biblioteca Argentina Juan Álvarez y La Bancaria, donde se realizaban encuentros de padres -en los que se charlaba sobre la dinámica del proyecto- y algunos talleres de apoyo escolar y educación sexual.

Ese momento fue concebido como una "transición" en la organización del proyecto editorial. Desde su origen barrial, con una estructura conformada por varias organizaciones, pasó a nuclear a varias familias desde el centro de la ciudad:

[...] ese momento fue como un momento de, cómo podría decirlo, de transición, de cambio dentro de cómo se venía manejando el proyecto, y se sumó un montón de gente, que son muchas de las familias que están hoy en día. Se sumó un montón de gente que ya trabajaba, estaba trabajando en el centro de Rosario, en la calle de Rosario, cosa que antes la revista apuntaba más a los pibes específicamente que estaban en la calle o algunos pibes que venían de otras organizaciones sociales o barriales que también la vendían, ¿no? Caso de los chicos de La Vagancia. En esa época, cuando yo me sumé, el proyecto hace un cambio y empieza a sumar gente, familias, estructuras familiares que estaban en la calle trabajando, no viviendo, trabajando. (R, comunicación personal, 11 de septiembre de 2012)

El proyecto editorial comenzó a abarcar también al grupo familiar: se incorporaron adultos y jóvenes desocupados para que tuvieran una entrada económica y la posibilidad de fortalecer los lazos familiares:

[...] nosotros al Ángel lo entendemos como un proyecto colectivo, [...] si bien los chicos [que] la venden dicen "la revista de los chicos de la calle", estos chicos tienen familia, pertenecen a un grupo familiar y nosotros siempre [...] les comentamos que la revista sea un proyecto de la familia en realidad. (N, comunicación personal, 28 de agosto de 2007)

[...] se fue dando naturalmente porque se empezaron a acercar las madres y los chicos más grandes que, a su vez, tenían chicos. La idea de la revista siempre fue que los chicos no estén en la calle. La idea era que esto se amplíe para [que] los que trabajen sean los más grandes, para que los chicos cumplan con su función [de] ir a la escuela, jugar y demás. (L, comunicación personal, 28 de noviembre de 2011)

Asimismo, se modificó la distribución de la revista y la lógica del reparto: los vendedores tuvieron que abonar los costos antes de salir a venderla. Esta medida fue tomada por los coordinadores debido a que, anteriormente, se les entregaba la revista de manera gratuita, pero notaron que luego muchos no volvían, por lo que "había que buscarle otra forma".

Entonces ahí también hubo un replanteo desde la organización de la revista, donde había que buscarle otra forma [...] se cambió un poco la lógica del reparto, que, a partir de esos números, se les empezó a vender a un precio de costo a las familias y, a medida que iban vendiendo, iban reponiendo números para seguir vendiendo. Y eso fue un cambio fundamental, me parece, le dio mucho crecimiento al proyecto. Empezó a crecer cada vez más la cantidad de gente, de familias que se acercaban hasta el centro para poder trabajar con el Ángel de Lata. (R, comunicación personal, 11 de septiembre de 2012) 
Para los coordinadores, esto significó una reorganización del equipo, de reuniones periódicas, de pensar y planear actividades con las familias vendedoras, de fomentar el vínculo con ellas. Un giro fue la implementación del acompañamiento en la venta por la peatonal, hacer un seguimiento y acompañamiento, dar "una vuelta para ver cómo andan los chicos". Esto se convirtió en una estrategia para retomar los vínculos, para poder charlar con las personas que vendían la revista. Otra de las maneras de fomentar el vínculo fue delegar el reparto de las revistas en uno de los jóvenes adultos que las vendía, "Ale", quien se transformó en un integrante importante del proyecto, lo que le permitió al grupo coordinador comenzar a ensayar actividades.

En un momento fuimos nosotros los encargados del reparto, lo hacíamos en algunas plazas, al reparto y a la venta Y después ya eso pasó a manos de unos de los adultos del Ángel, que es el Ale, que fue y se empezó a encargar él de hacer el reparto y la venta, y nosotros pasamos a acompañar, a estar ahí acompañando a la familia, a pensar los talleres o actividades que se fueron realizando. (R, comunicación personal, 11 de septiembre de 2012)

Esta lógica de reparto intentó evitar que entre los grupos familiares se gestaran relaciones competitivas y conflictivas:

Siempre [...] el núcleo fue la Plaza Pringles. Hubo un tiempo en que se repartió también y
se vendió, justamente por una cuestión que había crecido un montón la cantidad de gente,
de familias que venían a vender, se habían puesto dos bocas de expendio, que una era la
Plaza Pringles y la otra la Plaza Sarmiento. Eso [...] se había dispuesto así para evitar algu-
nos conflictos entre las familias que estaban emergiendo, ¿no? desde los que hacía mucho
que estaban y los nuevos que se sumaban, sobre todo por la zona en donde venden [...],
pero no pasó a grandes problemas. (R, comunicación personal, 11 de septiembre de 2012)

Uno de los objetivos del proyecto editorial en la plaza fue intentar conformar "estructuras de contención”, articulando las relaciones entre las familias y los voluntarios que se habían acercado al proyecto:

Cuando empecé a laburar, en esa época, [...] ya existía esta dinámica de la plaza. [...] Ahí lo que se intentaba era [...] armar estructuras de contención. Y después, bueno, va pasando eso que hay gente que sigue de largo y gente que se va quedando. [...] nunca tuvo una estructura sólidamente delineada, por lo menos desde que yo estoy, no sé qué pasó cuando arrancaron. Había muchas dificultades. Esto que vemos hoy nosotros, de los lazos entre ellos, implica determinadas cuestiones personales, de celos, competencias, esto siempre fue así desde que la estructura se armó en la plaza. La plaza siempre generó eso, también generó esto que, aquellos con personalidades más fuertes, más plantados, generaban esa mezcla de admiración y de bronca. (S, comunicación personal, 15 de noviembre de 2012)

Los conflictos internos ponían en evidencia la carencia o la debilidad estructural de la coordinación del proyecto editorial:

Ahí, en ese momento, " $\mathrm{N}$ " funciona como catalizadora de toda esa conflictividad, tratando de generar estos espacios de charla que por ahí se hacían en la plaza. Pero, digamos, 


\title{
Austral Comunicación \\ Volumen 10, número 1 (junio de 2021): 243-276 ISSN (I) 2313-9129. ISSN (E) 2313-9137
}

\begin{abstract}
no aparecía nunca la posibilidad de sistematizar nunca nada porque esta estructura era itinerante y errática. Se hacía difícil. Y también esto de que en cada encuentro era como que arrancabas otra vez, no era que había una continuidad. Tampoco era que se hacían encuentros todos los meses. (S, comunicación personal, 15 de noviembre de 2012)
\end{abstract}

Esta concepción de "estructura itinerante" del proyecto editorial era una percepción compartida por todos sus integrantes. En muchas ocasiones, se pensaba que era por la frecuencia con la que salía la revista. En efecto, era irregular, dado que dependía de muchos factores, como el económico, ya que cada número era financiado por el anterior más el aporte de la Fundación "M". Además, dependía de los tiempos personales del director, que estaba en España y enviaba a la editorial el dibujo de tapa, y de los de la editora, quien además estaba comprometida con otras actividades.

En este escenario se trataron de encauzar los lazos con los vendedores y organizar una estructura que sistematizara el trabajo: "Tenemos que tratar de que la revista tenga continuidad, de que salga cada dos meses, como también garantizar reunirnos todos los sábados acá en la plaza, comenzar a conocernos con la gente de nuevo, retomar los vínculos" (R, comunicación personal, 25 de julio de 2009).

Las reuniones se realizaban todos los sábados al mediodía. Allí se charlaba sobre diversas cuestiones a llevar a cabo, actividades, festejos especiales. En efecto, en la plaza se festejaron el día del niño, el de la madre, el de la primavera, se realizaron juegos con los niños, se abría un espacio de diálogo con los grandes en el que se hablaba de las condiciones de vida:

[...] sin agua, utilizan el carbón, enfermedades respiratorias. Las autoridades se acercan solo en época de elecciones para conseguir voto y después no hacen más nada, los medios no se acercan si no tan solo cuando alguien importante llama para quejarse de la gente de la villa. (A, comunicación personal, 8 de agosto de 2009)

Quedé con Sofi en encontrarme para dar apoyo escolar. Llegué y no estaba. Hablé con el Ale, estaban sus dos hijos.

- ¿Cómo andan con la venta?

-Bien - me dijo-, un poco lenta.

-Y está más cara -le dije.

-Sí, lo que pasa es que vos imaginate, una familia con tres chicos necesita 120 pesos para comer por día.

—Sí, y solo para comer - le dije-, sin contar los útiles para la escuela.

-Ni la ropa ni las zapatillas - agregó-, está difícil para todos. (A, comunicación personal, 11 de junio de 2010)

Sin embargo, la plaza tenía una impronta de encuentros y desencuentros: "No hay gente porque no hay más revistas". Esta situación se repetía de forma constante. La 
irregular frecuencia de salida de la revista causaba malestar en los vendedores, que se presentaban para hacerles reclamos a los coordinadores:

Llego y estaban dos madres de algunos chicos y adolescentes que venden la revista. Ahora estaban vendiendo ropa de segunda.

Hablamos un poco:

—Tendría que salir el próximo número de la revista, ¿tuvieron la reunión ustedes? —pregunta una de las madres.

-Sí, el martes, parece que la revista sale a fines de octubre.

En eso llega R. Nos saludamos. Mates preparados.

Una madre nos dice:

-Y... tendría que salir una revista ahora y la próxima antes de las fiestas.

-Y sí, eso trataremos de hacer. (Madres y R, comunicación personal, 17 de octubre de 2009)

Esto provocaba que el grupo coordinador tuviera que replantear su convocatoria y comenzar a organizarse más allá de la revista. En una de las reuniones semanales, " $\mathrm{R}$ " habló al respecto: "Tendríamos que armar espacios con las personas, que la revista sea algo aleatorio. Que cada uno piense qué quiere hacer en la plaza y llevarlo a cabo de manera coordinada. Organizar eventos" (R, comunicación personal, 18 de febrero de 2010).

El aspecto que dificultaba esta estrategia era la falta de un espacio concreto. Si bien la plaza se había configurado como un lugar de referencia, organizar actividades que requirieran concentración y encuentros se tornaba difícil, dado que se trataba de un espacio público y transitado. El deseo de tener un espacio que funcionara como "local" se hacía inminente, tal como veremos en el siguiente apartado.

Asimismo, este escenario evidenció la cuestión económica del proyecto, su circulación, la situación de la venta y la relación en el interior del grupo -editor, coordinador $\mathrm{y}$ vendedores-, quienes sostienen que una de las patas principales del proyecto fue constituirse como "una fuente de laburo":

Hay familias que se han hecho la casa, que han comprado cosas para la casa, [...] ves que cuando sale la revista los chicos tienen zapatillas nuevas, remeras [...]. Y eso era mucho más evidente en una situación económica mucho peor que la de ahora; ahora, en cierta medida, la situación económica avanzó. Pero en ese momento se veía mucho esa falta, y el tema de los chicos sobretodo. (L, comunicación personal, 28 de noviembre de 2011)

En la Marcha del Movimiento Nacional de los Chicos del Pueblo se presentó el proyecto editorial y su primer número. En esos primeros momentos, la publicación circulaba en festivales particulares, en facultades e institutos terciarios, como también en la peatonal. Era vendida mayoritariamente por los jóvenes de La Vagancia, que or- 
Austral @municación

ganizaban también la venta en la peatonal mediante una estrategia que no se trataba solo de vender, sino de contar lo que sucedía en el barrio, las problemáticas en las cuales estaban inmersos:

[...] no era que nosotros nos quedábamos en la peatonal ofreciendo a todos los que pasaban, sino que íbamos, juntábamos un redoblante y un bombo, nos íbamos a la peatonal y un grupo alrededor tocando y ofreciendo la revista a todo el mundo, y volándoles los pelos a la gente, diciéndoles: nosotros somos un barrio, hacemos esto, bla, bla, bla, somos un grupo de jóvenes, hacemos esta publicación porque queremos que se conozca lo que pasa en el barrio y la hacemos nosotros. (M, comunicación personal, 14 de octubre de 2012)

Esto mismo se refleja en cómo entendían la publicación. Para ellos, era un trabajo, poder llevar un ingreso a sus hogares y aportar a la economía familiar, pero también representaba contradicciones, ya que eran menores de edad que trabajaban mientras denunciaban el trabajo infantil $y$, al mismo tiempo, lo reivindicaban porque podían obtener un ingreso para sus familias:

[...] la revista para mí era una gran fuente de laburo [...] con la plata hacías lo que se te cantaba, comprarte unas zapatillas, comprarte ropa, [...] eso lo manejábamos nosotros. Yo le daba plata a mi vieja [...] también era una gran contradicción, porque uno cuando era más chico denunciaba esa cuestión de trabajo infantil, pero, a la vez, también uno elegía el trabajo, ¿entendés? Elegía trabajar. A mí nunca mis viejos me dijeron "andá a trabajar". (M, comunicación personal, 14 de octubre de 2012)

Esta cuestión del trabajo infantil era trabajada al interior del grupo coordinador y editor. Desde su surgimiento, el proyecto editorial se planteó como un espacio de contención para los chicos, considerando la cuestión económica a la par de la educativa, dado que la realidad les demostraba que esos chicos y sus familias ya se encontraban realizando trabajos ambulatorios. La revista se les presentó como un "trabajo más digno", en relación con que ofrecen un producto que habla de ellos:

[...] el origen del proyecto y el objetivo que tiene siempre es ese, que los chicos se sientan contenidos y que se sientan con pertenencia a un grupo y entonces planteamos esta cuestión. Pero ¿qué encontrábamos?, que cuando vos planteás proyectos que tienen que ver puramente con lo educativo, con lo recreativo, y no contemplás en ningún sentido la cuestión económica porque la realidad que ellos viven es muy dura, hacen agua muy rápidamente. Entonces nosotros lo que encontramos en una revista es que nos permite articular algunos talleres, hacer actividades con los chicos, que a ellos les sirve porque les da un ingreso. Y además, sinceramente, nos preocupaba que uno dice "bueno los chicos no tienen que estar trabajando", es cierto que los chicos no tienen que estar trabajando, tienen que estar jugando y es así, el tema es que esto existe [...] y que estos chicos estaban pidiendo moneditas, vendiendo curitas y que los basureen, y entonces nosotros lo que encontramos en la revista es un medio de trabajo más digno, si se quiere, porque de repente la revista los identifica más, tiene que ver con ellos, habla de su realidad y los posiciona en otro lugar a la hora de vender, porque los chicos ahora te dicen "yo antes mangueaba y ahora vendo", o sea, como que no es lo mismo. Ellos son los "chicos del Ángel de Lata" y cuando ellos van a algún lugar o viene alguien de la GUM [Guardia Urbana Municipal] 
o lo que sea ellos no dudan [...] de chapear con "yo soy del Ángel" o venir y contarnos y nosotros ahí hacemos las gestiones con quien sea necesario, si les hicieron algo, si los trataron mal. [...] tienen ese espíritu de cuerpo, "somos los chicos de la revista", y está bien que así sea. (N, comunicación personal, 28 de agosto de 2007)

Cuando la revista se instaló en el centro de la ciudad, en la Plaza Pringles, se integró a personas que estaban trabajando en la calle, en la venta de varios artículos, como modo de subsistencia. Allí comenzó a discutirse el tema de la mendicidad y la educación e imagen en la venta:

[...] la revista sí tuvo un avance en esa cuestión de no a la mendicidad [...] el producto tiene que ser interesante para que la gente lo compre [...], que los chicos no estén rogando para que se lo compren, que no estén descalzos, [...] porque el tema de la mendicidad tiene que ver con eso. (L, comunicación personal, 28 de noviembre de 2011)

[...] lo ideal sería, y nos encantaría, que ningún chico venda. De hecho, nosotros siempre pedimos que la revista se la compren a los más grandes, porque hay gente más grande vendiendo. Lo que pasa es que la mayoría de las familias ponen a los chicos también a vender porque, sinceramente, cuando un grande te vendió diez, un chico te vendió cincuenta, porque la gente le compra más a los chicos que a los grandes, y bueno, eso es así. (N, comunicación personal, 28 de agosto de 2007)

En el transcurso del trabajo de campo, conversamos con los chicos y chicas que vendían la revista, preguntándoles cómo se sentían con la venta, con quiénes iban a vender, cuál era la estrategia que utilizaban para llegar a los potenciales compradores y cómo se sentían tratados por aquellos. A continuación se citan unos extractos:

—Chicos, y con la revista ¿cómo se sienten? ¿Se sienten bien? ¿Es mejor que vender otra cosa?

-Sí, es mejor que vender pañuelitos, porque los pañuelitos te dicen "no quiero, gracias", o si no te dicen "tomátelas porque acá no se pueden vender".

- ¿Te tratan mal?

-Sí.

-Y vos ¿qué le decís?

—Nada, yo sigo caminando. [...]

-Y las revistas, ¿cómo las ofrecen? A ver, si vos me tendrías que vender una revista [risas]. Vendeme la revista, dale, ¿qué decís?

-Él dice "por favor, ¿te puedo hacer una preguntita? ¿Me comprás la revista del Ángel de Lata?

- ¿Y vos qué decís?

-Amiga, ¿me comprás la revista del Ángel de Lata de los chicos de la calle? Una sola, así después me quedan cuatro y me voy a mi casa. (Niños vendedores, comunicación personal, 10 de agosto de 2009)

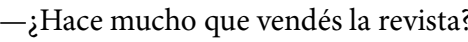

-Sí, no me acuerdo cuánto. 
Austral Comunicación

Volumen 10, número 1 (junio de 2021): 243-276

ISSN (I) 2313-9129. ISSN (E) 2313-9137

-Eras más chiquitita...

-Sí, venía con mi abuela a vender.

$-i Y$ ahora con quién estás viniendo?

-Sola.

- ¿Sola? Pero ¿te juntás con otros acá?

-Sí, con Florencia y mi hermana Verónica.

[...]

- ¿Te gusta?

-Sí.

$-¿$ Qué te gusta?

_ ¡Todo! Y aparte me ayuda porque antes robaba y ahora vendo la revista. La revista me parece una ayuda para mí porque también puedo llevar para comer a mi casa, que antes no había para comer. Antes tenía que salir mi hermano a robar. (Va, comunicación personal, 10 de diciembre de 2009)

- ¿Hace cuánto que estás vendiendo la revista?

-Cuatro años, por ahí.

- ¿La familia también o venís solo?

-No, mi hermana se queda por la peatonal Córdoba. Yo me voy a caminar.

$-¿ \mathrm{Y}$ te gusta vender la revista?

-Sí.

$-{ }_{\text {¿Por qué te gusta? }}$

-Y... ¡A Antes de andar robando!

$-¿ Y$ te sentís identificado con la revista?

- ¿En qué sentido identificado?

-Si la sentís como propia.

-Sí, me siento identificado, me gusta venderla. (W, comunicación personal, 10 de diciembre de 2009)

Como se observa, un común denominador es el maltrato que en general recibían de los potenciales compradores. En su mayoría, los chicos se acercaban solos a vender y en la peatonal se unían a otros. La revista les daba un sentido de pertenencia y contención al brindarles apoyo económico y social para ellos y sus familias. Por otra parte, la venta de la revista los apartaba de la delincuencia en la que incurrían para "poder comer":

Nos paramos en uno de los puestos donde se encontraba un padre y sus tres hijos. Roki saluda y nos presenta:

—Hola, ¿cómo va todo? Ellos son la gente que colabora, trabaja en la revista. 
- Hola, ¿cómo andan? Acá estoy con los pibes.

Saluda con un beso y se pone a hablar unas cosas con Roki, que no se logran escuchar bien, dado el bullicio de la peatonal al mediodía del sábado. Sus tres hijos estaban de espaldas, al lado del padre, con sus caras en la vidriera. En eso pasa un señor:

- ¡Cuiden a esos chicos! ¡La higiene! Se están refregando las caras y las manos en la vidriera - dice el señor, sin parar, sino que caminando realiza este comentario. Los niños se dan vuelta, sonrientes. En ese momento me doy cuenta de que en la boca tenían unas galletitas. Nadie hizo ningún comentario, Roki continuó hablando con el padre joven.

[...]

-Bueno, vamos a seguir caminando, ¿no sabes por dónde hay más vendiendo la revista? -le pregunta Roki al padre.

- Seguro que en Córdoba y Sarmiento, en Falabella hay un montón. Deben estar amontonados todos ahí.

-Yo acá estoy tranquilo vendiendo. Ya me conocen bastante. La del kiosco de enfrente me regala café, acá en las oficinas me dejan pasar al baño.

-Ya te conocen - comenta-, te tienen confianza.

-Sí, ya me tienen confianza. Si va cualquiera, no lo dejan pasar. Ahora, si van conmigo, sí -comenta con una sonrisa en la cara. ( $\mathrm{R}$ y vendedores, comunicación personal, $25 \mathrm{de}$ julio de 2009)

En esta escena se evidencian dos situaciones en las cuales se manifiesta la mirada de los demás. Ambas expresan lo que Goffman (2006) concibe como "escenas mixtas", en las cuales se enfrentan cara a cara "normales" y "estigmatizados". En el primer caso, se percibe un juicio estigmatizante por parte de un transeúnte, que rechaza sin reparos ni reflexión el estado de higiene de los hijos del vendedor de la revista, reclamando un propicio cuidado y un modo de actuar. En el segundo, el padre comenta una situación positiva de su posición en cuanto a la aceptación y ayuda que recibe de los negocios de los alrededores de donde él tiene su puesto de venta, habla de una construcción de su identidad como vendedor de la revista en la transformación de su estigma social. Las comunicadoras sociales Díaz, Lacombe y López (2002) expresan en su análisis esta misma situación para el caso de la revista La Luciérnaga en Córdoba:

[...] la fuerte incidencia del "juicio social de la mirada" en la construcción de su propia identidad: el ser conocidos como "chicos de la calle", genera en los mismos "estigmas" o valoraciones negativas de sus atributos identitarios que condicionan sus prácticas limitando su desarrollo social. [...] también pudimos reconocer el desarrollo de su trabajo como vendedores de la revista La Luciérnaga genera espacios en los cuales los chicos mejoran su relación con la comunidad mediante lo cual transforman aspectos de su identidad y logran mayor aceptación social. (p. 4)

Mediante la venta, van adquiriendo sentido de pertenencia al proyecto, a partir de lo cual se relacionan con los transeúntes, con los negocios circundantes. En esa interacción, Wilkis (2006), retomando los planteos de Goffman (2006), señala sobre 
Austral Comunicación

Volumen 10, número 1 (junio de 2021): 243-276

ISSN (I) 2313-9129. ISSN (E) 2313-9137

las estrategias que emplean los vendedores (en este caso, de La Luciérnaga) en el acto de la venta:

El problema no consiste en manejar la tensión que se genera durante los contactos sociales, sino más bien en manejar la información que se posee acerca de la deficiencia. [...] Orquestar una interacción o intercambio para los vendedores supone transitar por dicho dilema que remite a qué información social transmitir. Los signos organizativos, principalmente la revista y el acompañamiento de algún tipo de discurso referido al contenido de la publicación, la organización y la propia condición del vendedor son parte de los recursos que ellos disponen para llamar la atención. (Wilkis, 2006, p. 114).

Se observa que en el acompañamiento de la venta de la publicación se trata de conversar sobre situaciones que no están ocurriendo en ese momento, sino sobre la vida y las problemáticas de las personas vendedoras:

\footnotetext{
Me acerco para escuchar y estaban hablando de una hijita de él, que acaba de nacer con la clavícula quebrada:

-Es un caso de mala praxis - le dice una de las chicas participantes del Ángel de Lata.

-Sí, estamos viendo de hacer algo judicial, pero el abogado nos cobra mil pesos - comenta el padre.

-Pero podés conseguir abogados gratuitos - le comenta " $R$ ".

-Sí, eso estamos viendo. (R y vendedores, comunicación personal, 25 de julio de 2009)
}

\section{Tercer escenario: Casa del Estudiante}

A mediados de 2010, la Subsecretaría de Vinculación Comunitaria de la Facultad de Ciencias Médicas de la Universidad Nacional de Rosario concedió en préstamo en la Casa del Estudiante un salón de grandes dimensiones. Ese espacio reforzó las intenciones del grupo coordinador y talleristas de fortalecer el vínculo con las familias vendedoras y sus allegados, y así comenzar a efectivizar actividades con ellas.

El trabajo de los talleres se desarrolló apuntando a cinco ejes:

1. Diagnosticar las dificultades en el aprendizaje formal-escolar para vehiculizar la intervención en las situaciones que requirieran apoyo escolar o de alfabetización.

2. Propiciar espacios de reflexión, debate y encuentro de las distintas problemáticas que surgieran tanto en la convivencia durante las actividades como en las conversaciones que surgen en las situaciones de trabajo y recreativas, consumo, sexualidad, violencia, relación con pares y no pares. 
María Cecilia Telleria

Comunicación y construcciones de identidad en el Ángel de Lata (Rosario, 2000-2012)

3. Generar espacios de aprendizaje de oficios para que cada uno de los participantes se nutra de recursos y herramientas que lo habiliten a proyectarse a futuro y a corto plazo.

4. Estimular las potencialidades expresivas, desarrollar las posibilidades propioceptivas, experimentar con distintos materiales y técnicas. Dar paso a la creatividad y al goce.

5. Producir material, desde las posibilidades de cada taller, para ser publicado en la revista. En la medida en que cada vez más lo producido sea de chicos, jóvenes y adultos, que luego son los canillitas que ofrecen la revista por distintos lugares de la ciudad, es lícito pensar que vender la revista adquiera otro sentido. (S, escrito, 20 de octubre de 2010)

En los primeros encuentros en el nuevo espacio, todo el esfuerzo de talleristas, vendedores de la revista y familias se centró en la organización y acondicionamiento: desde la limpieza del salón y los sanitarios hasta cortar el pasto del jardín.

Luego, se dio lugar a una de las primeras reuniones con las familias y los talleristas. La coordinadora de los talleres, aquí llamada "S", consideraba a este nuevo espacio como un "lugar de pertenencia"."Ale", distribuidor de la revista, lo confirmaba como un lugar de pertenencia cuando enfatizaba que había que "valorizar el proyecto", haciendo referencia al Ángel de Lata, que "a partir de este espacio, se podrían difundir y comunicar las actividades a través de la revista, por lo que habría que hablar con la editora para que abra el espacio de edición" (A, comunicación personal, 19 de marzo de 2011).

Las primeras actividades propuestas fueron de plástica, en la cual se les enseñó el moldeado en cerámica y macramé, entre otras técnicas; diseño de indumentaria, en la que se trabajó en la confección de nuevas prendas como también en el arreglo de aquellas que ya no usaban; y danza árabe. Al comienzo, estos talleres estaban organizados en dos turnos, mañana y tarde, con la intención de darles apoyo escolar a los chicos que lo requirieran; también se emprendió el proceso de alfabetización de los adultos a través del método cubano "Yo sí puedo". Luego, se sumaron talleres de yoga, computación, periodismo, costura, construcción de horno de barro y panificación. Comenzaron a asistir las familias que vendían la revista y luego ellos llevaban grupos de chicos conocidos del barrio, que comenzaron a conocer el proyecto editorial Ángel de Lata. Además, la Casa posibilitó formalizarse en un espacio concreto para la realización de la residencia de estudiantes de Psicología, cuestión que se formalizó en el transcurso de 2012 tras conversaciones con la decana de la facultad de esa carrera. También en ese año se participó del proyecto \#Colectivo de Miradas\#, del departamento de Educación del Museo de la Memoria de la ciudad de Rosario, el cual se trataba de encuentros con organizaciones o proyectos sociales vinculados con la construcción de la memoria y el abordaje de los derechos humanos desde lo comunitario. 


\section{Austral Comunicación \\ Volumen 10, número 1 (junio de 2021): 243-276 ISSN (I) 2313-9129. ISSN (E) 2313-9137}

El trabajo en la Casa implicaba varias cuestiones, sobre todo organizativas: ¿quién tiene las llaves? ¿Quién va? ¿Qué actividades hacemos? Implicó que en un mismo tiempo y espacio se encontraran diferentes edades y situaciones, por lo que se planteó realizar actividades por grupos de edad. La estrategia era acondicionarlo para que los talleres no se solaparan ni se dificultaran en su desarrollo, por lo cual, comenzaron a realizarse distintos días de la semana. La asistencia por parte de los vendedores y allegados era un tanto errática, es decir, a veces concurrían, otras no, mediando sobre todo la cotidianeidad de estos. Todo esto se reflejó en el grupo de los talleristas y fue materia de reflexiones:

[...] organizar y concretar más cada taller (día, horario, actividad, etc.). Aunque creo que estamos en lo que llamo una "etapa de seducción". Los hechos nos demostraron que cuando quisimos llevar a cabo cada taller en un día distinto no funcionó. (E, comunicación personal, 10 de septiembre de 2011)

Estoy de acuerdo en que los talleres existen y tienen entidad en tanto haya quienes los habiten, pero poder conceptualizar intentando en este recorrido dar cuenta de "lo hecho y de lo por hacer" quizás sea una forma de revertir lo que hoy sucede: una clara merma en la cantidad de asistentes. Lo del miércoles, en el taller de costura, puede pensarse como algo coyuntural, aunque no deja de ser preocupante pensado desde el grupo en su conjunto. Si es pensado desde las historias particulares, las razones por las que cada uno no llegó al taller muchas veces son dramáticas, tienen que ver con su cotidianeidad áspera y complicada. (S, comunicación personal, 10 de septiembre de 2011)

Yo creo que si bien hay motivos por los que se dan las ausencias, también a lo largo de este tiempo hubo muchos motivos por los cuales la elección de muchos fue estar presente. Tal vez deberíamos empezar a pensar en ordenar un poco más el tiempo de cada cosa y planificarlas y darles continuidad para que todos los que hacemos el taller estemos en la misma "onda" y dejemos de andar tan dispersos. (J, comunicación personal, 10 de septiembre de 2011)

Igualmente creo que hay que hacer unas reuniones, tal vez cada quince días, y también hablarlo con ellos, ver cuáles son las cosas que quieren y que les interesan más. (Ju, comunicación personal, 10 de septiembre de 2011)

Disponer de la Casa del Estudiante resaltaba cuestiones de convivencia entre talleristas y asistentes:

Pienso que tenemos que tener una actitud coherente, unificada, todos los que participamos de esto. Pienso que nos tenemos que organizar más en esas pequeñas cosas. Si no, se hace muy pesado. Además, en la medida en que no colaboren o estén ahí con responsabilidad y buena onda, nunca van a sentir propio del todo el lugar. Con respecto a esto, yo tengo la idea de que falta diálogo, que sepan por qué cada uno de nosotros está ahí, quiénes somos, de dónde venimos. (C, comunicación personal, 10 de noviembre de 2011)

Frases tales como "uno tiene algo planificado y la realidad te muestra otra cosa" o "ni siquiera sabemos exactamente con quiénes trabajaremos la víspera de cada sábado" eran recurrentes entre los talleristas de la Casa. Todos estos factores -de convivencia 
junto con la dinámica de los talleres, que se experimentaba "dispersa"- dieron lugar a que se plantearan algunas estrategias de acción. La ronda de bienvenida representó una de ellas, por la cual se realizaba una presentación de los asistentes y talleristas, de las propuestas de actividades que se habían pensado y la posibilidad de proponer nuevas. Otra de las estrategias fue la posibilidad de mantener reuniones entre los talleristas con el fin de reflexionar sobre el trabajo en la Casa:

\begin{abstract}
Adhiero y coincido con que las reuniones propician la unión y el diálogo entre nosotros. Son los momentos donde nos comunicamos, coincidimos, disentimos, compartimos lo que nos preocupa e inquieta, lo que anhelamos, deseamos en relación a nuestro trabajo compartido. Es una instancia necesaria para nuestro crecimiento y fortalecimiento como grupo de trabajo. (S, comunicación personal, 20 de septiembre de 2011)
\end{abstract}

Se suma a lo anterior la escasez de recursos materiales. La Cooperadora de la Facultad de Ciencias Médicas aportaba para los gastos diarios necesarios de la merienda, y la Fundación "M", financiadora del proyecto editorial, aportaba en lo que fuera necesario, como tarjetas de colectivo y materiales necesarios para los talleres. Otro aporte lo realizaban algunas librerías mayoristas que dejaban sus artículos a un precio accesible. Asimismo, se comenzó a pensar en distintas posibilidades de financiación de las actividades. Una de ellas fue la venta de los bonos contribución, organizada junto a una murga uruguaya conocida de la ciudad:

\footnotetext{
Qué bueno que la venta de los bonos nos esté permitiendo disponer de dinero que antes no disponíamos y poder efectivizar lo del horno, las mini pelotas, los trajes para las nenas, todas cosas que hace dos meses solo estaban en el plano de lo deseado: hoy lo pudimos concretar. (S, comunicación personal, 10 de noviembre de 2011)
}

Otra cuestión que se trabajaba era la articulación con distintos organismos para contener y acompañar a los chicos y adultos que asistían a la Casa, como se trabajaba en años anteriores. Articulación con espacios municipales, provinciales y nacionales. Así se explayaba "S" en una reunión, quien fue la que mantuvo esa relación y esos encuentros:

La idea es poder pensar estrategias de acompañamiento en conjunto para intentar garan-
tizar una mejor escolaridad en los chicos que lo necesiten. Me fui con la agradable sensa-
ción de que quizás todo esto dé paso a un salto cualitativo en nuestro laburo, que las tres
chicas con las que hablé están seriamente comprometidas con su tarea y que armar una
red que habilite y contenga es posible. (S, comunicación personal, 20 de agosto de 2012)

Se acordó con las directoras de las escuelas realizar un listado de los chicos que asistían a los talleres e iban a su escuela, para luego hablar con las maestras y poder hacer un acompañamiento más efectivo, según las necesidades de cada chico. 


\title{
Austral @municación \\ Volumen 10, número 1 (junio de 2021): 243-276 ISSN (I) 2313-9129. ISSN (E) 2313-9137
}

"L", editora de la publicación, se expresó sobre estos temas de la relación con los chicos y las familias que vendían la revista, de darle preponderancia a que los chicos dejaran de estar en la calle trabajando y que "estén ocupando sus lugares de niños tanto en la escuela, de juego y demás, porque en realidad, más allá de que haya un espacio de talleres, los chicos tienen un trabajo".

\begin{abstract}
Los talleres tienen que trabajar en ese tema de los chicos trabajando en la calle. Y, por otro lado, me parece que es importante generar otros espacios donde la revista comience a venderse desde los más grandes, digamos, yo incluso con la gente que estoy hablando, en vecinales y demás, ya la revista no la van a vender los chicos, la idea es que la revista la vendan los grandes. [...] Entonces, mi idea es justamente eso, incorporar nuevas familias, pero incorporar a los grandes, no a los chicos. Que yo creo que eso va a ser una vuelta de tuerca, va a ser una como un avance, como un paso más delante de la revista. (L, comunicación personal, 28 de noviembre de 2011)
\end{abstract}

En definitiva, la concesión de un espacio significó la reafirmación de los objetivos del proyecto Ángel de Lata, de constituirse como una herramienta que configurara y dinamizara un espacio de contención educativa y recreativa, además de posibilitar paliar las emergencias económicas a través de la puesta en circulación de la publicación.

\section{Reflexiones finales}

A partir del proceso presentado en este artículo y de las investigaciones halladas sobre la problemática, se considera que los medios de comunicación comunitarios -en particular el proyecto editorial Ángel de Lata-construyen desde sus prácticas y desde sus condiciones de producción identidad y pertenencia, debido a que se constituyen en portadores de sentido social producto de grupos de personas nucleados en una construcción colectiva. En otras palabras, un medio de comunicación comunitario genera vínculos que construyen sentido social, debido a que configura un universo en el cual las personas que lo producen (el grupo coordinador) y sus receptores (las familias vendedoras) lo apropian, provocando en ambos sentidos identidad y de pertenencia.

De esta manera, se reconoce que el objeto de la investigación antropológica es el estudio de los métodos de construcción de sentido en las distintas sociedades que dependen tanto de iniciativas individuales como de formas simbólicas colectivas. Augé (1996) define el sentido social como "el conjunto de relaciones simbólicas instituidas y vividas entre los unos y los otros en el seno de una colectividad que dicho sentido permite identificar como tal" (p. 11). Por lo tanto, el sentido social se define, según el autor, mediante dos relaciones: identidad/pertenencia y alteridad.

Este sentido de identidad se encuentra arraigado a la noción de "pertenencia social", entendida aquí como: 


\begin{abstract}
La inclusión de la personalidad individual en una colectividad hacia la cual se experimenta un sentimiento de lealtad. Esta asunción se realiza generalmente mediante la asunción de algún rol dentro de la colectividad considerada [...] pero sobre todo mediante la apropiación e interiorización al menos parcial del complejo simbólico-cultural que funge como emblema de la colectividad en cuestión. (Giménez, 1997, p. 13)
\end{abstract}

En esta línea, Castells (2004) argumenta que "la identidad es la fuente de sentido y experiencia para la gente" (p. 29). Como la construcción social de la identidad se realiza en un contexto marcado por las relaciones de poder, propone una distinción entre tres formas y orígenes de la construcción de la identidad:

- Identidad legitimadora: es la introducida por las instituciones que dominan una sociedad para extender y racionalizar su dominación. Esta identidad genera una sociedad civil organizada.

- Identidad de resistencia: es la producida por actores que se encuentran en una situación subordinada por la lógica de la dominación. Esta identidad conforma comunidades.

- Identidad proyecto: es una nueva identidad que construyen los actores sociales basándose en los materiales culturales de que disponen, redefiniendo su posición en la sociedad y buscando transformar su estructura social. Esta identidad produce sujetos:

[...] actor social colectivo mediante el cual los individuos alcanzan un sentido holístico en su experiencia. En este caso, la construcción de la identidad es un proyecto de una vida diferente, quizás basado en una identidad oprimida, pero que se expande hacia la transformación de la sociedad como la prolongación de este proyecto de identidad. (Castells, 2004, p. 32)

Es a partir de esta última que se comprende el proyecto editorial Ángel de Lata en su objetivo de constituirse como un soporte comunicacional, económico, afectivo y educativo de las personas que nuclea, proceso que conlleva, además, la reconstrucción permanente de este en referencia a la conformación de grupos de coordinación y a nuevas familias que se integran y reintegran al proyecto. En palabras de una de sus vendedoras:

[...] cambia el hecho de vender la revista porque la revista habla de nuestros chicos, de Rosario, es algo que gusta, la gente la colecciona, y en muchos casos nos vienen a comprar. El trato es diferente. Nos acostumbramos a vender y no pedir. Entre todos tenemos que sostener la casa, no hay otra manera. Además, es bueno que los chicos aprendan, y me parece que es mejor que vendan una revista y no que tengan que salir a robar para comer. La gente tendría que entender más, ayudar más. (E, comunicación personal, 20 de agosto de 2007)

La intención de este artículo fue responder la pregunta sobre qué procesos hicieron a la construcción del proyecto editorial Ángel de Lata como espacio de articulación, 


\section{Austral Comunicación \\ Volumen 10, número 1 (junio de 2021): 243-276 ISSN (I) 2313-9129. ISSN (E) 2313-9137}

identidad y pertenencia en la ciudad de Rosario. A través de los relatos, se visibilizaron estos procesos y los sentidos que se fueron construyendo desde los distintos escenarios que fue habitando desde su surgimiento: el barrio Ludueña, la Plaza Pringles y la Casa del Estudiante.

En el primer escenario, el barrio Ludueña, se considera que el proyecto editorial trataba de construirse en un espacio de articulación, identidad y pertenencia para los actores sociales que participaban. Así, en un primer momento, el sentido de pertenencia estaba representado por estar organizado de modo colectivo en cuanto al proceso de producción. Estos actores sociales se encontraban identificados con nociones de comunicación alternativa y popular, por lo que su acción se hallaba determinada con que la revista fuera "hecha por y para los pibes". Tanto el armado de la publicación como el acto de la venta se constituyeron en un hecho colectivo, pues se discutían los contenidos y se vendía entre todos, repartiendo lo recaudado entre los participantes.

En el segundo escenario, la Plaza Pringles, se observa que la revista se constituyó, tanto para el grupo editor/coordinador de la venta como para las familias vendedoras/ talleristas, en una oportunidad económica, una herramienta de trabajo, una "fuente de laburo". Si bien se trataba de generar una estructura de contención educativa y recreativa, según el grupo coordinador "hacían agua" si no consideraban lo económico. Desde el grupo editorial y acompañante en la venta, se reconoce que se trataba de grupos domésticos en los que todos los miembros de la familia aportaban en lo económico. Argumentan que era una "realidad que ya existía", ya se encontraban niños realizando venta ambulante por las peatonales rosarinas, y que ellos les estaban brindando un producto con el cual se sentían identificados.

En el tercer escenario, la Casa del Estudiante, se evidencia el desarrollo de uno de los objetivos del proyecto editorial, el que se planteó desde sus inicios como una propuesta educativa de contención, de pertenencia de niños y adolescentes, brindando espacios educativos y de expresión a través de talleres. Estamos hablando de las prácticas socioculturales del proyecto editorial Ángel de Lata, en las cuales la revista se presentaba como una "excusa", considerando las estrategias puestas en juego de los actores sociales involucrados y el reconocimiento de estos. Sin embargo, se percibió que siempre había que arrancar de nuevo, ya sea porque la revista no estaba en circulación y costaba proyectar, porque no se tenía un espacio estable donde realizar los encuentros y talleres o porque se contaba con el espacio, pero costaba llevar adelante un trabajo orgánico como Ángel de Lata.

Desde los escenarios mencionados, se contempló el proyecto editorial Ángel de Lata como un medio de comunicación encargado de transmitir las realidades vividas en cada uno de ellos y las experiencias de vida de sus vendedores, que no son difundidas por los medios hegemónicos de comunicación, o, si lo hacen, lo realizan instalando 
María Cecilia Telleria

Comunicación y construcciones de identidad en el Ángel de Lata (Rosario, 2000-2012)

en la sociedad prejuicios que fortalecen procesos hegemónicos que refuerzan la exclusión. En este sentido, se comprende que la labor de quienes producían la revista y de los talleristas apuntara a trascender la exclusión, es decir que, mediante la publicación y las prácticas socioculturales que promovía Ángel de Lata, les posibilitara a los vendedores entramar relaciones de identidad y pertenencia, posicionarse para poder construir de manera flexible y colectiva relaciones sociales en constante transformación.

\section{Referencias}

Achilli, E. (2005). Investigar en antropología social. Los desafíos de transmitir un oficio. Ed. Laborde.

Alucín, S. y Denardi, L. (2012). Moralidades, educación popular y pobreza: un estudio comparativo de experiencias educativas confesionales en Rosario y Gran Buenos Aires. ${ }^{\circ} 2$ Jornadas de Investigadores en Formación. Reflexiones en torno al proceso de investigación, IDES. Buenos Aires, Argentina, 14 al 16 de noviembre de 2012. https://static.ides.org.ar/archivo/giif/2012/11/Educacion-Alucin-Denardi.pdf.

Araujo Albrecht, R. (2009). La Luciérnaga, revista de los chicos de la calle. Del cambio social a la empresa social (Tesina de Licenciatura). Universidad de Buenos Aires, Buenos Aires. http://comunicacion.sociales.uba.ar/wp-content/uploads/ sites/16/2013/02/2319.pdf.

Augé, M. (1996). El sentido de los otros. Actualidad de la antropología. Paidós.

Barturen, M. (1997). El fenómeno de la prensa social. Revista de Servicios Sociales, (31), 44-54. http://dialnet.unirioja.es/servlet/articulo? codigo=2699202.

Buffarini, M. (2008). Transformaciones en el espacio urbano. Las personas sin hogar y los usos del espacio urbano público. Revista de la Escuela de Antropología, XIV, 191-200.

Castells, M. (2004). La era de la información. Economía, sociedad y cultura (Vol. II). Siglo XXI.

Díaz, C., Lacombe, E. y López, C. (2002). El Juicio de la Mirada. Incidencia de la mirada social en la construcción y resignificación de los atributos identitarios. Análisis de un caso particular: Los chicos trabajadores de La Luciérnaga (Tesina de licenciatura). Universidad Nacional de Córdoba, Córdoba.

Fasano, P. y Roquel, E. (2015). Comunicación comunitaria: un proyecto en busca de definiciones. Actas de Periodismo y Comunicación, 2(1), 1-9. http://sedici. unlp.edu.ar/bitstream/handle/10915/62617/Documento_completo.pdf-PDFA. pdf?sequence $=1$.

Franco, D. (2002). "Hecho en Buenos Aires": un proyecto editorial para los sin techo (Tesina de licenciatura). Universidad de Buenos Aires, Buenos Aires. http:// comunicacion.sociales.uba.ar/wp-content/uploads/sites/16/2013/02/1196.pdf. 
García Canclini, N. (1995). Culturas Híbridas. Estrategias para entrar y salir de la modernidad. Sudamericana.

Giménez, G. (1997). Materiales para una teoría de las identidades sociales. Frontera Norte, 9 (18), 9-28. https://fronteranorte.colef.mx/index.php/fronteranorte/article/ viewFile/1441/891.

Goffman, E. (2006). Estigma. La identidad deteriorada. Amorrortu.

Gutner, E. (2016). La representación de la cultura en el discurso de los indigentes (Tesis doctoral). Universidad Nacional de Rosario, Santa Fe. https://rephip.unr.edu.ar/ xmlui/handle/2133/11395.

Hall, S. y Du Gay, P. (Comps.). (2003). Cuestiones de identidad cultural. Amorrortu.

Heram, Y. (2008). Contracultura, democracia y medios. Un análisis del El Porteño. XII Jornadas Nacionales de Investigadores en Comunicación. Rosario, Santa Fe, Argentina, 16 al 18 de octubre de 2008.

Kejval, L. (2016). Ante la Ley. Reconfiguraciones de la identidad política de las radios comunitarias, populares y alternativas argentinas (1983-2015) (Tesis doctoral). Universidad de Buenos Aires, Buenos Aires.

Marioni, L. (2018). Participación de jóvenes en medios de comunicación comunitarios, alternativos y populares en la Región Centro, Argentina. Una aproximación para su estudio. Revista Brasiliense de Pos-graduacao em Ciencias Sociais, 14(1), 38-58. https://ri.conicet.gov.ar/handle/11336/113474.

Martín Barbero, J. (1991). De los medios a las mediaciones. Editorial Gustavo Gili.

Martín Barbero, J. (2004). Oficio de Cartógrafo. Fondo de Cultura Económica.

Mata, M. (2000). Reflexiones acerca de las investigaciones en comunicación. Revista Latina de Comunicación Social, (35). http://revistalatinacs.org/ argentina2000/01cmata.htm.

Melella, C. (2010). Prensa migrante. La construcción de la identidad boliviana en el periódico Renacer. XIV Jornadas Nacionales de Investigadores en Comunicación. Buenos Aires, Argentina, 16 al 18 de septiembre de 2010.

Rama, Á. (1998). La ciudad letrada (Trabajo original publicado ca. 1984). Arca.

Rockwell, E. (2011). La experiencia etnográfica: historia y cultura en los procesos educativos. Paidós.

Sigarusa, C. (2006). Las revistas políticos-culturales locales: construirse desde La Orilla. $\mathrm{X}$ Jornadas Nacionales de Investigadores en Comunicación. San Juan, Argentina, 19 al 21 de octubre de 2006.

Vinelli, N. y Rodríguez Esperón, C. (2004). Contrainformación. Medios alternativos para la acción política. Continente.

Verón, E. (1985). El análisis del "Contrato de Lectura", un nuevo método para los estudios de posicionamiento de los soportes de los media. En Les Medias: 
Comunicación y construcciones de identidad en el Ángel de Lata (Rosario, 2000-2012)

Experiences, recherches actuelles, applications. Institut de recherches et d'études publicitaires. https://semioticaderedes-carlon.com/wp-content/uploads/2018/04/ veron-analisis_del_contrato_de_lectura.pdf.

Wilkis, A. (2006). Un análisis del circuito de donación surgido a partir de las "publicaciones de la calle" en la ciudad de Buenos Aires. Avá, Revista de Antropología, (9), 108-131. http://www.ava.unam.edu.ar/images/09/pdf/ava09_08_wilkis.pdf. Williams, R. (2009). Marxismo y literatura. Las Cuarenta. 